\title{
Testing the Efficacy of Nanoparticles, Biological Formulation with the qPCR Technique to Improve HLB Management
}

\author{
Shloke Patel \\ Hillsborough Highschool, 2218 Branch Hill Street, Tampa, Florida, 33612, USA; shlokep8@gmail.com
}

\begin{abstract}
Citrus phloem bacteria, Candidatus Liberibacter asiaticus (CLas), causes the citrus greening disease, Huanglongbing (HLB). In 2019, this devastating disease caused a 21\% decrease in the fresh citrus fruit market and a $72 \%$ decline in the commercially grown production of oranges in Florida. The number of Florida industry jobs dropped by $59 \%$ compared to previous years. HLB has no cure; global orange juice production is expected to fall by double digits in the coming years. Typical symptoms include yellowing of the leaves, as well as lopsided, premature, and bitter fruits. Since, CLas hides deep within the citrus phloem, commercial antibiotic sprays often cannot reach the bacteria. A biological solution for the prevention of the detrimental effects of HLB was used; the formulations tested were combined with copper nanoparticles which would potentially increase the penetration and the longevity of the formulation to mitigate the effects of the greening disease. The formulations included Firewall and Fireline, two approved and readily available antibacterial solutions, and a bioformulation, curry leaf extract.

The experiment was conducted in a greenhouse with 42 infected plants with five leaf samples being collected from each plant. The DNA of the leaves was extracted using the GeneJET DNA purification Kit. 6 formulations: Firewall with and without nanoparticles, Fireline with and without nanoparticles, curry leaf extracted with and without nanoparticles were prepared and injected into six plants. After 3 months, the bacterial DNA concentration was determined, and 4 physical parameters of the plant were measured. The formulations were injected again, and after 70 days, qPCR assay and physical parameters were measured. Then, both the CT values and physical parameters were collected and compared.

The bacterial count remained unchanged in the treatment and control variables, the three physical parameters, trunk diameter, plant height, and width all improved compared to the control variable.

KEYWORDS: Biology; Agriculture; Huanglongbing; Candidatus liberibacter; Nano formulation; GeneJET.
\end{abstract}

\section{- Introduction}

The Citrus production in Florida is limited by the impact of various biotic and abiotic factors. Of all the citrus limiting factors, Huanglongbing (HLB) or citrus greening is the most prominent and rampant in spreading throughout a grove in just matter of weeks. Although Florida has favorable conditions and is best suited for citrus production, it is very prone to HLB. Citrus greening disease has devastated millions of acres of citrus crops throughout the United States and abroad. ${ }^{1}$ Florida is the largest orange-producing state in the United States and the third-largest orange producer in the world behind Brazil and China. The citrus industry makes roughly 45,000 full time and part-time jobs and contributes 8.6 billion a year to Florida's economy. ${ }^{1}$ Since HLB was first found in 1998, orange acreage and yields in Florida have decreased by $26 \%$ and $42 \%$, respectively. ${ }^{2}$ Orange production dropped from 242 million to 104.6 million boxes in 2014 and if this negative trend continues, Florida will not have a profitable orange industry soon. ${ }^{2}$ In the current scenario, farmers are faced with the threat of losing their orange grove to this disease. Currently, the only short-term viable solution entails antibiotics which wash away after a month or two with devastating effects on the soil. Additionally, many unknown side effects are caused by these antibiotics. However, Florida has still allowed these chemicals to be sprayed on the orange plants without any proven utility of the Firewall and Fireline solutions being demonstrated. Many researchers have been experimenting with the use of minuscule particles called nanoparticles. These 100-nanometer particles can easily penetrate a cell wall allowing the antibiotic to seep through phloem. ${ }^{3}$ These particles are currently used in medical and technological fields but are scarcely used in the agricultural field.

Citrus greening disease (Huanglongbing) is caused by a bacterial infection (Candidatus liberibacter), which spreads through an insect vector called Asian Citrus Psyllid (ACP). Psyllid adults feed on citrus greening-infected trees and acquire the bacteria through the bacterial residue on the vector's mouth. The psyllid then carries the bacteria from an infected plant to a healthy plant. Next, the psyllid injects the bacteria onto a healthy plant while feeding and transfers the greening disease into the plant's phloem, affecting the vascular system and limiting nutrient uptake. ${ }^{4}$ The disease reduces yield, fruit size, and quality and increases tree mortality and production costs. Once the orange tree is infected with the greening disease, the tree eventually dies within a few years. ${ }^{5}$ Currently, many nanoparticles are being used as fungicides due to the elements' antibacterial properties. ${ }^{6}$

Nanoparticles are made of many conventional materials that change mechanical properties when they are formed into nanoparticles. Nanoparticles have a greater surface area per weight than larger particles, which causes them to be more reactive to large particles. These small particles usually come in 
the form of metals for the agricultural sciences because many phloem or xylem-limited bacteria are not easily penetrable by regular antibiotics. ${ }^{7}$ Nanoparticles such as copper bind to the bacteria, and because of copper's antibacterial properties, they eliminate the bacteria. Research shows that engineered nanoparticles that are metalloids have demonstrated an activity that kills harmful plant bacteria. Many metalloids are known for being bactericides and or fungicides but are not used conventionally. Nano-fertilizers have also been very useful in improving plant health by entering the phloem of the plant. Some nanoparticles act as antimicrobial agents, while others alter the nutrition of the plant. Penetration of the vascular tissue occurs when a particle is sufficiently small so that it can seep through the cell wall. During a process called adhesion, the nanoparticle bends the cell wall, and eventually, the cell wall wraps around the nanoparticle. ${ }^{8}$ In large quantities, the penetration can be beneficial and can play a role in mitigating disease, which might lead to a reduction in the use of heavy metals and other chemicals.

\section{- Methods}

\section{Analysis and Procedure:}

The experiment was conducted in a greenhouse with 42 infected plants. The psyllid repellency was determined by the prevention of the reinfection of the plant, validated through the CT value. Since this was a short-term experiment, immediate symptoms were tested through the measurement of the physical parameters. Fireline and Firewall have extremely toxic chemicals such as oxytetracycline hydrochloride ${ }^{16}$ in Fireline and Streptomycin ${ }^{13}$ in Firewall which are helpful in killing the bacteria. Samples were collected from each plant to determine the concentration of the greening bacteria through qPCR assay. DNA was extracted using the Gene JET DNA purification Kit.

The initial PCR measurements were used to ensure that all the plants had the same CT value to provide consistent data.

\section{Plant Measurements:}

The trunk diameter was measured using the vernier caliper for each of the 42 plants. Plant width was determined by the spread of the leaves that are the farthest from each side of the plant. The plant height was measured by the trunk of the plant that was above soil level to the tip of the plant, vertically. The plant width and plant height were measured using a measuring tape.

\section{Plant Vigor:}

The plant vigor is a researcher-based observation on the total fullness of the plant. Variables such as the color of the leaves are taken into consideration. In this experiment a 0-10 scale was used to calibrate the plant vigor.

\section{Chlorophyll Measurements:}

The chlorophyll concentrator meter used was the Apogee Meter which measures the content in $\mu \mathrm{mol}$ per $\mathrm{m}^{2}$. To measure the chlorophyll content, a leaf was placed between the arm of the meter and the base of the meter, and the leaf was pressed against by the arm which detected the chlorophyll. The data then was gathered in the appendix of the system and was uploaded to excel.

\section{qPCR preparation :}

The qPCR technique provided an essential piece of data when determining the bacterial count, the $\mathrm{CT}$ value. There are 3 steps in the process of the qPCR technique which include the denaturation, primer annealing, and extension. The qPCR solution requires $10 \mu \mathrm{L}$ of TAQMAN qPCR buffer which is comprised of $8.6 \mu \mathrm{L}$ of sterile deionized water, CQUL Primer and the leaves of the plants.

\section{Arbo Jet Injection Preparation:}

An opening in the trunk is required to inject the 6 solutions into the plants. A $4 \mathrm{~mm}$ hole was drilled into each of the 42 plants using the drilling machine. Once the path into the plant was created, $60 \mathrm{~mL}$ of the desired solution was injected into a one-year-old plant. The injection was slowly administered to prevent the disruption of the flow of nutrients in the phloem and xylem. The process took approximately 8 hours for the solution to be fully administered.

\section{Psyllid Repellency:}

The psyllid repellency was determined by the CT value, which was an indicator for the bacterial count. The physical parameters also helped in validating the $\mathrm{CT}$ value results.

\section{Results and Discussion}

The psyllid repellency was tested using 7 treatments including the control variable. Treatment 1 was the controlled variable, and treatments 2 and 3 were the industry standards, Fireline and Firewall, respectively. Treatments 4 and 5 were the industry standards with the nano formulation, and treatments 6 and 7 were the bioformulation, curry leaf extract, without the nano formulation and with the nano formulation, respectively.

The following parameters were studied during the evaluations of the results. The parameters monitored include, increase in the height, increase in the width of the stem, increase in the trunk diameter, increase in the chlorophyll content as a measure of the overall plant health and average increase in the plant vigor (Table 1 through Table 7).

Table 1: Average Increase in Plant Traits of the 42 Citrus Plants through 2 Growing Seasons.

\begin{tabular}{|l|r|r|r|r|r|r|r|}
\hline Treatment & Trt 1 & Trt2 & Trt 3 & Trt 4 & Trt 5 & Trt 6 & Trt 7 \\
\hline 6 replications) & & & & & & & \\
\hline Avg. increase in ht (ft) (6 replications) & 0.35 & 0.55 & 0.73 & 0.7 & 0.57 & 0.6 & 0.52 \\
\hline $\begin{array}{l}\text { Avg. increase in width (ft) (6 } \\
\text { replications) }\end{array}$ & 0.2 & 0.38 & 0.53 & 0.43 & 0.37 & 0.52 & 0.53 \\
\hline $\begin{array}{l}\text { Avg. increase in Trunk diameter (ft) } \\
\text { Avg. increase in Chlorophyll content } \\
\left(\mu \mathrm{mol} \mathrm{m}^{\wedge}-2\right)\end{array}$ & 0.17 & 0.27 & 0.31 & 0.42 & 0.39 & 0.21 & 0.27 \\
\hline \begin{tabular}{l} 
Avg. increase Plant vigor (0-10 scale) \\
\hline
\end{tabular} & -0.37 & 0.47 & 0.53 & 0.47 & -0.27 & -0.16 & 0 \\
\hline
\end{tabular}

Table 1 shows the average increases of all the plant traits taken for the 7 treatments and 6 replications, through the 2 growing seasons. 
Table 2: Average Plant Vigor of the 42 Citrus Plants through 2 Growing Seasons (0-10 scale).

\begin{tabular}{|c|c|c|c|c|c|c|c|}
\hline Time Treatments & Trt 1 & Trt 2 & Trt 3 & Trt 4 & Trt 5 & Trt 6 & Trt 7 \\
\hline Start & 8.2 & 8.2 & 8.3 & 8.2 & 8.6 & 7.83 & 8 \\
\hline 3 months & 7.83 & 8.33 & 7.5 & 7.67 & 7.83 & 8 & 7.5 \\
\hline 5.5 months & 7.83 & 8.67 & 8.83 & 8.67 & 8.33 & 7.67 & 8 \\
\hline Percent Increase & 0.37 & 0.47 & 0.53 & 0.47 & 0.27 & 0.16 & 0 \\
\hline Standard Deviation & 0.21 & 0.24 & 0.67 & 0.50 & 0.39 & 0.17 & 0.29 \\
\hline
\end{tabular}

Table 2 shows the average plant vigor on a $0-10$ scale for the 7 treatments for the 6 replications. There was a significant increase in treatment 3 with an increase of plant vigor of 1.33 .

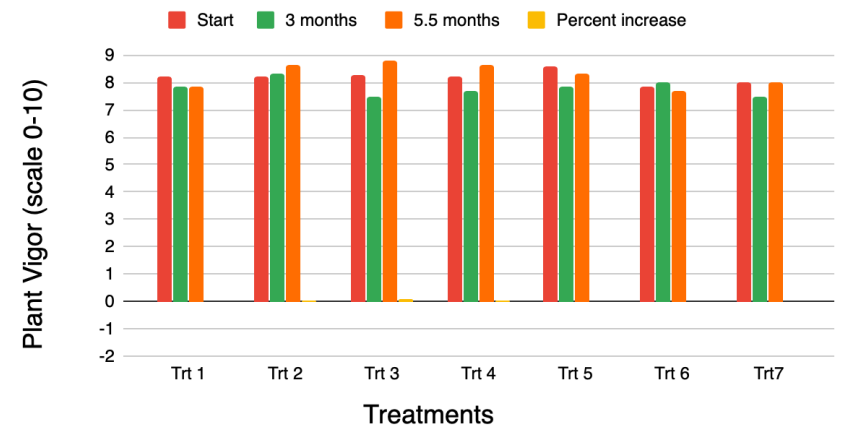

Figure 1: Average increase in Plant Vigor..

Most of the treatments started with a plant vigor of around 8. As the bacteria moved towards the phloem the plant vigor decreased and at 5.5 months the plant vigor started to increase. Treatment 3 had the highest plant vigor at 5.5 months (Figure 1).

Table 3: Average Height of the 42 Citrus Plants through 2 Growing Seasons $(\mathrm{ft})$.

\begin{tabular}{|c|c|c|c|c|c|c|c|}
\hline Time & Treatment & Trt 1 & $\operatorname{Trt3}$ & $\operatorname{Trt~4~}$ & $\operatorname{Trt5}$ & $\operatorname{Trt} 6$ & $\operatorname{Trt7}$ \\
\hline Start & 1.8 & 1.82 & 1.87 & 1.92 & 1.92 & 1.78 & 1.8 \\
\hline $\mathbf{3}$ months & 1.94 & 2.01 & 2.05 & 2.11 & 2.23 & 2.1 & 2.1 \\
\hline $\mathbf{5 . 5}$ months & 2.13 & 2.37 & 2.6 & 2.67 & 2.7 & 2.38 & 2.32 \\
\hline Percent Increase & $18.33 \%$ & $30.22 \%$ & $39.04 \%$ & $39.10 \%$ & $0.60 \%$ & $33.71 \%$ & $28.89 \%$ \\
\hline Standard Deviation & 0.17 & 0.28 & 0.38 & 0.39 & 0.35 & 0.30 & 0.26 \\
\hline
\end{tabular}

Table 3 and Figure 2 shows the average height of the 42 citrus plants through the two growing seasons, approximately 5.5 months. Treatment 4 had an average percent increase of
$39.10 \%$, which was the largest increase of all the 7 treatments.

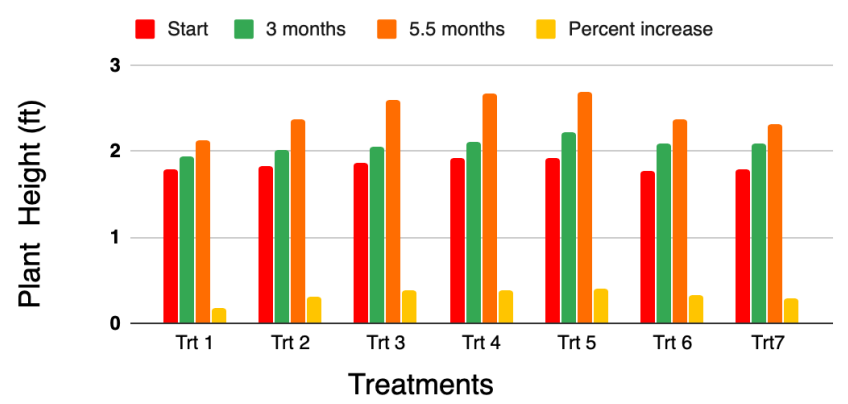

Figure 2: Average height increase.

As shown by the Table 3 above after a period of 5.5 months a more drastic increase was shown compared to the interval of the start to 3 months of the experiment.

Table 4: Average Width of the 42 Citrus Plants through 2 Growing Seasons (ft).

\begin{tabular}{|c|c|c|c|c|c|c|c|}
\hline Treatments & Trt 1 & Trt 2 & Trt 3 & Trt 4 & Trt 5 & Trt 6 & Trt 7 \\
\hline Start & 1.3 & 1.3 & 1.32 & 1.28 & 1.3 & 1.3 & 1.35 \\
\hline 3 months & 1.35 & 1.42 & 1.45 & 1.4 & 1.45 & 1.52 & 1.5 \\
\hline 5.5 months & 1.5 & 1.68 & 1.85 & 1.73 & 1.67 & 1.82 & 1.82 \\
\hline Percent Increase & $15.39 \%$ & $29.23 \%$ & $40.15 \%$ & $35.16 \%$ & $28.46 \%$ & $40 \%$ & $9.82 \%$ \\
\hline Standard Deviation & 0.10 & 0.19 & 0.28 & 0.23 & 0.19 & 0.26 & 0.24 \\
\hline
\end{tabular}

Table 4 shows the average width of the 42 citrus plants through the 2 growing seasons (approximately 5.5 months). Over the span of 2 growing seasons treatment 3 showed the largest percent increase in the width of all the treatments.

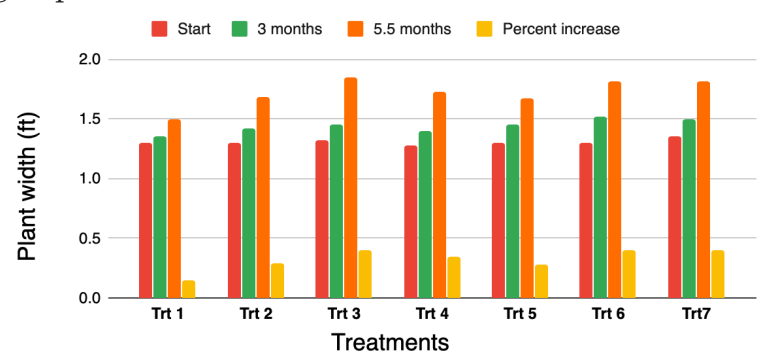

Figure 3: Average Width increase.

The average width percent increase is shown in the Figure 3 of all the treatments for the 6 replications.

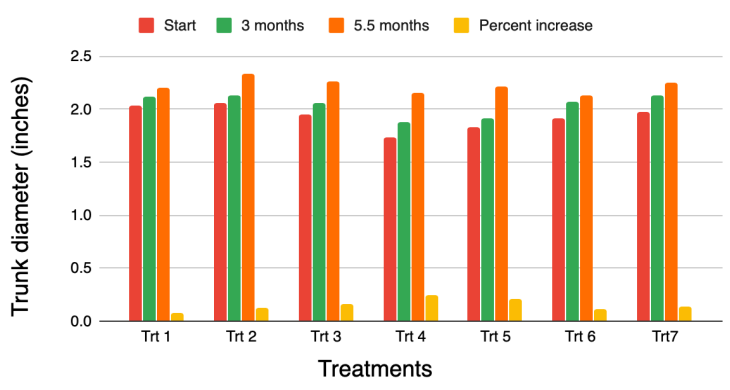

Figure 4: Average Trunk Diameter increase. 
There was a positive trend between the amount of time and the increase in the trunk diameter in the 7 treatments.

Table 5: Average Trunk Diameter of the 42 Citrus Plants through 2 Growing Seasons (inches).

\begin{tabular}{|c|c|c|c|c|c|c|c|}
\hline Treatments & Trt 1 & Trt 2 & Trt 3 & Trt 4 & Trt 5 & Trt 6 & Trt 7 \\
\hline Start & 2.03 & 2.06 & 1.95 & 1.73 & 1.83 & 1.92 & 1.98 \\
\hline $\mathbf{3}$ months & 2.12 & 2.13 & 2.06 & 1.88 & 1.91 & 2.07 & 2.13 \\
\hline $\mathbf{5 . 5}$ months & 2.2 & 2.33 & 2.26 & 2.15 & 2.22 & 2.13 & 2.25 \\
\hline Percent Increase & $8.30 \%$ & $3.11 \%$ & $5.90 \%$ & $24.28 \%$ & $21.31 \%$ & $10.94 \%$ & $13.84 \%$ \\
\hline & & & & & & & \\
\hline
\end{tabular}

This data was significant because there was a significant increase of growth between 3 months and 5.5 months showing that the treatments had an effect, which was allowing the phloem and xylem to expand. Treatment 4 had the highest percent increase of the average trunk diameter of $24.28 \%$.

Table 6: Average Chlorophyll Content of the 42 Citrus Plants through 2 Growing Seasons.

\begin{tabular}{|c|c|c|c|c|c|c|c|}
\hline Treatments & Trt 1 & Trt 2 & Trt 3 & Trt 4 & Trt 5 & Trt 6 & Trt 7 \\
\hline Start & 288 & 275.67 & 285 & 284.5 & 290.33 & 287.5 & 285.67 \\
\hline $\mathbf{3}$ months & 302.5 & 286.83 & 296.33 & 297.12 & 303.67 & 301 & 297.33 \\
\hline $\mathbf{5 . 5}$ months & 329.2 & 301.5 & 317.33 & 318 & 323.5 & 319.5 & 319.83 \\
\hline Percent Increase & $11.31 \%$ & $9.37 \%$ & $11.39 \%$ & $11.77 \%$ & $11.43 \%$ & $11.13 \%$ & $11.96 \%$ \\
\hline Standard Deviation & 20.90 & 12.95 & 16.40 & 16.92 & 16.69 & 16.06 & 17.36 \\
\hline
\end{tabular}

Due to the large standard deviations, the abnormal production of chlorophyll and chlorophyll deficiency are seen in later stages of HLB so fewer conclusions can be made from this data.

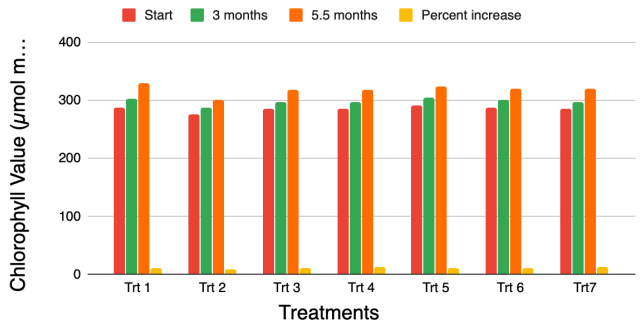

Figure 5: Average Chlorophyll content.

The plant is producing the required nutrients at the higher rate as it has more chlorophyll which is displayed by data in the table (Figure 5 and Table 6).

\section{qPCR Assay:}

The controlled environment in the greenhouse provided more controlled variables than experimenting in the field because the CT value did not change before and after 3 months. The physical parameters were measured using the qPCR technique. A scale of the acceptable $\mathrm{CT}$ values in relation to the bacterial population was created. A CT value below 17 indicates high levels of bacterial infection and a CT value of above 32 indicates that there is little to no bacteria present

Table 7: Average CT value of the 42 Citrus Plants through 2 Growing Seasons.

\begin{tabular}{|c|c|c|c|c|c|c|c|}
\hline Treatments & Trt 1 & Trt 2 & Trt 3 & Trt 4 & Trt 5 & Trt 6 & Trt 7 \\
\hline Start & 26.96 & 25.98 & 25.16 & 25.69 & 25.69 & 23.55 & 24.7 \\
\hline $\mathbf{3}$ months & 24.33 & 25.53 & 25 & 23.93 & 24.62 & 24.62 & 23.98 \\
\hline $\mathbf{5 . 5}$ months & 25.65 & 25.76 & 24.15 & 24.96 & 25.16 & 24.09 & 26.19 \\
\hline $\begin{array}{c}\text { Standard } \\
\text { Deviation }\end{array}$ & 1.32 & 0.23 & 0.54 & 0.88 & 0.54 & 0.54 & 1.23 \\
\hline
\end{tabular}

The difference between the starting CT value and the CT value after 5.5 months roughly stayed between 0 and 1 showing that the bacterial count remained consistent.

The CT value might have changed over time (Table 7) because of the bacteria's behavior concerning the temperature, but not enough time was given to access this variable. To see more accurate results of the bacteria usually 6 months is needed. ${ }^{2}$ During the 6 months either the plant will show significant symptoms or display no signs of symptoms. The hypothesis was accurately tested due to the data given by the 4 physical parameters. The physical parameters provided an accurate method to measure the bacterial content by examining characteristics including whether the plant was displaying or not displaying early symptoms such as blotchy mottle, yellowing of the leaves and veins.

The standard deviation was between 1.32 and 0.23 for the CT values, which shows that the data varies between 1.32 and 0.23 units from the mean CT value on average. In the experiment, the CT value of each plant was recorded before experimenting. 42 out of the 49 plants that had similar CT values were selected for this experiment. The change in the CT values should be comparable if all the plants have identical CT values.

Many researchers have tested the effectiveness of curry leaf extract on different vectors and the results have been positive due to azacytidine, an active antibacterial compound found in curry leaf. ${ }^{17}$ The expected results of this experiment were that since copper nanoparticles are also anti-bacterial, they would improve the efficacy. Currently, the efficiency of the addition of nano formulation in the plant vascular system is unknown.

The CT value in the table shows the number of cycles it takes for the PCR to detect the bacteria. Treatment 7 had the highest increase of the CT value which means the bacterial content decreased the most over the period of 5.5 months. 


\section{Conclusion}

The hypothesis was contradicted because the introduction of the nanoparticles did not prove to have a large impact on the CT value. According to the data collected in this experiment, the amount of Candidatus liberibacter bacteria stayed constant with the treatment of the six formulations injected in the infected citrus plants.

Currently, the treatments seem to have little effect on the CT value of the bacteria. As per the data collected the CT value has remained consistent with the highest standard deviation of 1.32 units over a period of 5.5 months. The treatment that showed the most improvement over the time span of 5.5 months was treatment 7 , the bioformulation with nano particles.

The change in the CT values did not prove that the nanoparticles helped with penetration of the antibiotics or curry leaf extract at 5.5 months, but there was a positive trend in the physical traits. Because of the flush formation process when the sap from the xylem tissue moves to the phloem tissue, the CT value remains the same, but it causes a better development of plant foliage. When the sap flows from the phloem to the xylem tissue, the bacterial concentration might decrease in the leaf, resulting in the increase in the CT value. Continuing this experiment for one full year might allow more time to see a difference in the CT value, since it covers the 4 cycles of the sap movement.

\section{- Acknowledgements}

My sincere gratitude to my mentor Dr. Balaji Aglave for guiding me through this project and offering his insight and expertise on this topic. I could not have completed this experiment without the help of Florida Agricultural Research. I sincerely thank them for permitting me to conduct my experiment on their premises. I also thank my science teacher Ms. Mishell Thomas-King for taking her time out of her day to help me with my project by giving me tips on my research plan. I thank my mom and dad for taking me to the research center.

\section{References}

1. Asian Citrus Psyllid and Huanglongbing in California. https:// californiacitrusthreat.org/pest-disease/

2. http://entnemdept.ufl.edu/creatures/citrus/acpsyllid.htm

3. Asian Citrus Psyllid. https://www.aphis.usda.gov/aphis/resources/ pests-diseases/hungry-pests/the-threat/asian-citrus-psyllid/asiancitrus-psyllid

4. Grafton-Cardwell, B., n.d. The Asian Citrus Psyllid and the Citrus Disease Huanglongbing. [ebook] Available at: <https://ucanr.edu/ sites/mgfresno/files/133416.pdf>

5. Useche, A. S. and P.Impact of Citrus Greening on Citrus Operations in Florida. https://edis.ifas.ufl.edu/fe983

6. Food and Resource Economics Department (FRED). https://fred. ifas.ufl.edu/economicimpactanalysis/publications/2015-citrusindustry/

7. 2021. Afrox 2017 INTEGRATED REPORT. [ebook] Available at: <https://www.afrox.co.za/en/images/Afrox_IR_11244_ v8b_20180410_LN\%20\%28002\%29_tcm266-468473.pdf >

8. 2021. Safety Data Sheet - Copper Nanoparticles. [ebook] Available at: <https://www.acsmaterial.com/pub/media/catalog/product/s/d/ sds-copper_nanoparticles.pdf>

9. Ortiz, J.; says:, R. L.; says:, L. B. How do Nanoparticles Enter Cells? https://sustainable-nano.com/2014/08/19/how-donanoparticles-enter-cells/
10.Elmer, W., Ma, C. and White, J., 2018. Nanoparticles for plant disease management. [ebook] Available at: <https://portal.ct.gov/-/ media/CAES/DOCUMENTS/Biographies/Elmer/Elmer-MaWhite-NP-for-P1-Diseae-Management-2018.pdf?la=en>

11.2013, W. by A. Z. N. M. 26. Copper (Cu) Nanoparticles Properties, Applications. https://www.azonano.com/article. aspx?ArticleID $=3271$

12.2018. Safety Data Sheet - Copper $(\mathrm{Cu})$ Nanoparticles / Nanopowder. [ebook] Available at: <https://n.b5z.net/i/ u/10091461/f/MSDS-NANOPOWDERS/US1089.pdf>

13.2014. Material Safety Data Sheet - Firewall. [ebook] Available at: $<$ http://agrosource.net/wp-content/uploads/2018/07/firewall-50sds-use-this-one.pdf $>$

14.2017. MATERIAL SAFETY DATA SHEET - LIQUID NITROGEN. [ebook] Available at: <https://www.afrox.co.za/en/ images/Nitrogen266_92436_tcm266-401695.pdf>

15.2016. Thermo Scientific GeneJET Plant Genomic DNA Purification Mini Kit \#K0791, \#K0792. [ebook] Available at: <https://assets.thermofisher.com/TFS-Assets/LSG/ manuals/MAN0016131_GeneJET_Plant_Genomic_DNA_ Purification_Mini_Kit_UG.pdf >

16.2011. Material Safety Data Sheet - FineLine. [ebook] Available at: https://assets.greenbook.net/M104560.pdf

17.Kumar, J., Sharma, V. K., Singh, D. K., Mishra, A., Gond, S. K., Verma, S. K., Kumar, A., and Kharwar, R. N. (2016, February 4) Epigenetic Activation of Antibacterial Property of an Endophytic Streptomyces coelicolor Strain AZRA 37 and Identification of the Induced Protein Using MALDI TOF MS/MS. PloS one. Public Library of Science.

\section{- Author}

Shloke Patel is a junior at Hillsborough High School. Growing up around farms, Shloke developed a deep understanding of the beneficial effect of farm fresh food on health. From a young age Shloke took inspiration in gardening by creating a backyard garden and enjoying fresh vegetables and fruits. He hopes to make a positive impact in the field of agricultural research. 